\title{
Brine shrimp cytotoxicity, phytochemical screening and larvicidal activities of plectranthus barbatus extracts
}

\author{
Lawi Y, Saria J and Kidukuli AW* \\ The Open University of Tanzania, Department of Physical Sciences, P.O .Box 31608. Dar es Salaam, Tanzania
}

\begin{abstract}
The genus Plectranthus (Lamiaceae) represents a large and widespread group of species with a diversity of traditional medicinal uses in the world. The new findings from Plectranthus barbatus ethanolic extracts revealed that cytotoxicity lethality based on Artemia salina Leach in roots are active with $\mathrm{LC}_{50}=40.07 \mu \mathrm{g} / \mathrm{mL}$ followed by twigs and leaves with $\mathrm{LC}_{50}=66.12 \mu \mathrm{g} / \mathrm{mL}$ and $186.33 \mu \mathrm{g} / \mathrm{mL}$ respectively. All plant parts contained Saponins, Terpenoids and Glycosides as a mojor principal group of secondary metabolites. Extract from Leaves are more active in Anopheles gambiae with $\mathrm{LC}_{50}=55.65 \mu \mathrm{g} / \mathrm{mL}$ followed by twigs and roots with $\mathrm{LC} \mathrm{F}_{50}=465 \mu \mathrm{g} / \mathrm{mL}$ and $\mathrm{LC}_{50} 636 \mu \mathrm{g} / \mathrm{mL}$ at 72 hours exposure respectively. Twig extracts showed moderate effect on both A.gambiae and A.eagyptiae after 48 hours and $72 \mathrm{hours}$ exposure time with $100 \%$ (MRC) Mortality Rate Concentration of $>1000 \mu \mathrm{g} / \mathrm{mL}$.
\end{abstract}

\section{Introduction}

Mosquitoes cause more human suffering than any other organism, they transmit several diseases like malaria, dengue fever, yellow fever, filariasis, schistosomiasis and Japanese encephalitis [1]. Here, malaria parasites are transmitted largely by mosquitoes of the Anopheles gambiae complex, which is the most efficient vector system in the world. This complex consists of a number of mosquito species that vary in their ability to transmit falciparum malaria in Africa [2]. Aedes aegypti is very important vector, transmitting the arbvovirus causing dengue haemorrhagic fever (HDF) and chikungunya in human [3]. At present, no effective vaccine is available for both dengue and malaria; therefore, the only way of reducing the incidence of this disease is by mosquito control, which frequently depends on applications of conventional synthetic insecticides which is not biodegradable [4]. On the other side of nature, the plants powder and plant extracts are sometimes more effective and environmental friendly than the synthetic pesticides and these phytochemicals have major role in mosquito control program [5-7].

Malaria is a major global health disease that affects humans, and it predominates in Africa and other areas with tropical climate [8]. Globally, an estimated 3.3 billion people were at risk of malaria in 2011, worldwide there are 104 countries and territories in which malaria is presently considered endemic [9]. In countries where the disease is endemic, pregnant women and children are most at risk. In epidemic areas, both adults and children are at risk [8]. In Tanzania, over $93 \%$ of Tanzania mainland population lives in areas where malaria is transmitted. The level of transmission is high in Lake Zone regions, Coastal regions and Southern lowlands. Malaria is still a leading cause of outpatient, inpatient and hospital deaths with 60-80 thousands estimated death per year mainly in children [10].

All over the world an estimated 2.5 billion people are at risk of dengue in tropical and subtropical areas [11]. This disease infection causes a spectrum of symptoms from mild flu-like to severe life threatening haemorrhage [12]. In recent years, Dengue fever and chikungunya affect most parts of the coastal areas of Tanzania and hence increasing burden to the health sector $[13,14]$.
The genus Plectranthus (Laminaceae) represents a large and widespread group of species with a diversity of traditional medicinal uses. The genus comprises a group of around 300 species, distributed in tropical and subtropical areas of Africa, Asia and Australia [15]. One of the interesting species of this genus is Plectranthus barbatus Andr.,which is well-known for the treatment of various ailments. A diversity of the traditional medicinal uses of P.barbatus in India (Hindu and Ayurvedic),East and Central Africa, China and Brazil have been reported to treat many diseases [16].The majority of uses are for intestinal disturbances and liver fatigue, respiratory disorders, heart diseases and certain central nervous system disorder [16-20]. Clinical studies of the plant and the forskolin constituent support these traditional uses and they have other benefit such as prevention of cancer metastases [21] and for the veterinary purposes [22]. Furthermore, its essential oils in tube has very attractive and delicate odour with spicy which act as an antimicrobial agent $[23,24]$.

The aim of this study was to evaluate the efficacy of ethanolic extracts from P.barbatus for larvicidal activity and safety using Artemia salina Leach as a test organism in cytotoxity activity. Moreover, the preliminary screenings of phytochemical constituents are evaluated.

\section{Materials and methods}

\section{Materials}

The plant materials parts (roots, leaves and twigs) of P.barbatus species were collected from Temeke District, Dar es Salaam, Tanzania

Correspondence to: Kidukuli AW, The Open University of Tanzania, Department of Physical Sciences, P.O.Box 31608. Dar es Salaam, Tanzania, Tel: +255 755861 283; E-mail: kidukuli@yahoo.com

Key words: Aedes aegyptiae, Anopheles gambiae, Brine shrimp Cytotoxicity, Plectranthus barbatus

Received: February 26, 2018; Accepted: March 24, 2018; Published: March 29, 2018 
in February, 2014. The samples were identified and authenticated in the Department of Botany, University of Dar es Salaam. The Brine Shrimps eggs were purchased from Aquaculture innovations (Grahamstown 6140.South Africa) and sea salt was prepared locally by evaporating water collected from the Indian Ocean, along the Dar es Salaam Coast. Mosquito larva Anopheles gambiae and Aedes eagyptiae., were obtained from Tanzania Pesticides Research Institute, TPRI-Arusha, Tanzania, whereas ethanol (absolute) was bought from Flika Chemie GmbH (Sigma-Aldrich ${ }^{\oplus}$.Zwijndrecht,Netherlands) and Dimethyl sulfoxide (DMSO), were purchased from Sigma ${ }^{\oplus}$. Potassium hydroxide $(\mathrm{KOH})$, Sodium Hydroxide $(\mathrm{NaOH})$, Acetone,Chloroform, were purchases in the Dar es salaam , Tanzania. Acids (sulphuric acid, Tartaric acid, Hydrochloric acid) were purchases from,Sigma-Aldrich ${ }^{\circledR}$ Zwijndrecht. Netherlands.

\section{Extraction process}

The roots, leaves and twigs of P.barbatus were separately dried, grinded to fine powders and later soaked twice in methanol for 48 hours. After that they were separately filtered and further concentrated using a rotary evaporator. The extracts were kept in refrigerator and later subjected to various chemical tests, bioassays and secondary metabolites screening to detect the presence of different useful natural product groups.

\section{Cytotoxicity lethality assay}

Artemia salina Leach larvae were used as indicator animals for preliminary cytotoxicity assay of the extracts [25]. The artificial seawater was prepared by dissolving sea salt $(3.8 \mathrm{~g})$ in distilled water to make a concentration of $3.8 \mathrm{~g} / \mathrm{L}$ and then filtered to remove the undeserved particles. The media solution was filled into a tank that has been divided into two unequal compartments by perforated polythene wall. Shrimp eggs were later sprinkled into the covered part of the tank and a lamp was illuminated on the uncovered part in order to attract the hatched auto-tropism shrimps. The mature nauplii were collected in between 36 and 48 hours of hatching [25]. The P. barbatus extracts were dissolved in Dimethyl sulfoxide (DMSO) in vials in duplicate at an initial concentration $240 \mu \mathrm{g} / \mathrm{mL}$ and decreasing up to $24 \mu \mathrm{g} / \mathrm{mL}$. In every vial containing the extract in solution, 10 brine shrimp larvae were added. An additional set of vials containing only a solvent (DMSO) in 5 $\mathrm{mL}$ of artificial seawater and $10 \mathrm{shrimp}$ larvae acted as control [25]. The number of survived larvae was established after 24 hours and the $\mathrm{LC}_{50}$ values of the concentrations required to kill $50 \%$ of the shrimp larvae, the concentrations to give $100 \%$ mortality rates concentration (MRC) and confidence intervals (CI) were obtained using probit analysis [26].

\section{Testing for larvicidal activity}

The larvicidal test was performed according to World Health Organization (WHO) protocol with minor modification [27]. The stock solutions $(50 \mathrm{mg} / \mathrm{mL})$ of plant extracts were prepared by first dissolving in DMSO. The stock solutions were diluted with distilled water to make $100 \mathrm{~mL}$ each, of $500,250,100$ and $50 \mu \mathrm{g} / \mathrm{mL}$ solutions of plant extracts. Ten late third instars laboratory reared Anopheles gambiae and Aedes aegyptiae larvae were separately then introduced in the test solution and mortality was observed after $24 \mathrm{~h}, 48 \mathrm{~h}$ and $72 \mathrm{~h}$. Negative control tests contained mosquito larvae DMSO $(0.5 \%)$ and water only. All tests were carried out in duplicate under controlled temperature $\left(25 \pm 2^{\circ} \mathrm{C}\right)$ and relative humidity of $75-85 \%$. The number of dead larvae was recorded after $24 \mathrm{~h}, 48 \mathrm{~h}$ and $72 \mathrm{~h}$ and the mean percentage mortalities calculated for each concentration. There after the mortality rate concentrations (MRC) were derived from the regression equations.

\section{Phytochemical screening of natural product group}

Phytochemical screening of natural product groups are performed according to the following standard protocol as described below;

Screening for saponins: About $0.5 \mathrm{~g}$ of the plants extract was shaken with water in a test tube. Frothing which persist on warming was taken as a preliminary evidence for the presence of Saponins. Few drops of olive oil was added to $0.5 \mathrm{~g}$ of extract and vigorously shaken. Formation of soluble emulsion in the extract indicates the presence of saponin [28].

Screening for tannin: Into $10 \mathrm{~mL}$ of freshly prepared $10 \%$ potassium hydroxide $(\mathrm{KOH})$ in a beaker, $0.5 \mathrm{~g}$ of extract was added and shaken to dissolve. A dirty precipitate observed indicate the presence of tannin [28-29].

Screening for alkaloids: The filtrate was shaken into 3 beakers: Three gram of extract was stirred with ethanol containing $3 \%$ tartaric acid. The filtrate was shared into 3 beakers and tasted for alkaloids as follows: Into the first beaker, Hagar's reagent was added into the second beaker; Mayer's reagent was added and into the third beaker Marquin's reagent was added. Precipitations in any of the 3 tests indicate the presence of alkaloid [28,30].

Screening for cardiac glycoside; (Keller Killiani test): Total 100 $\mathrm{mg}$ of extract was dissolved in $1 \mathrm{~mL}$ of glacial acetic acid containing one drop of ferric chloride solution. This was then under layered with $1 \mathrm{~mL}$ of concentrated sulphuric acid $\left(\mathrm{H}_{2} \mathrm{SO}_{4}\right)$. A brown ring obtained at the interface indicates the presence of a de-oxysugar characteristic of cardenolides [28-30].

Terpenoids: $0.2 \mathrm{~g}$ of the each extract was mixed with $2 \mathrm{ml}$ of chloroform and concentrated $\mathrm{H}_{2} \mathrm{SO}_{4}(3 \mathrm{ml})$ was carefully added to form a layer. The formation of a reddish brown coloration at the interface indicates positive results for the presence of terpenoids [28-30].

\section{Result and discussion}

The phytochemical screening from Table 1 revealed that saponins are present in both roots and leaves; however the activity differs due to the difference in concentration of the compound responsible for the action. These findings are supported by the recent study on phytochemistry, ethanobotanical uses and pharmacology review on the same plant species $[15,16]$. On the other side the polar group of natural product that is normally water soluble played a big role on the activities. Since on leaves part revealed less or no activity due to lack of this group. Hence the presence of saponins and glycosides as a water soluble natural product group played a big role on these activities as indicated in the Table 1.

Moreover from Table 2; the larvicidal activity in leaves are more active than the other parts with $\mathrm{LC}_{50}=55.65 \mu \mathrm{g} / \mathrm{ml}$ at 72 hours exposure time in Anopheles gambiae, this is followed by twigs and roots at $\mathrm{LC}_{50}$ of $465.67 \mu \mathrm{g} / \mathrm{ml}$ and $636.01 \mu \mathrm{g} / \mathrm{ml}$ respectively. Generally, Aedes egyptiae are more resistance towards P.barbatus ethanolic extract than

Table 1. Phytochemical screening of Plectanthus barbatus Ethanolic extract

\begin{tabular}{|c|c|c|c|c|c|}
\hline \multirow{2}{*}{ Plant parts } & \multicolumn{5}{|c|}{ Group of natural products } \\
\cline { 2 - 6 } & Saponins & Tanins & $\begin{array}{c}\text { Cardiac } \\
\text { glycosides }\end{array}$ & Alkaloids & Terpenoids \\
\hline Twigs & $\sqrt{ }$ & $\mathrm{X}$ & $\sqrt{ }$ & $\sqrt{ }$ & $\sqrt{ }$ \\
\hline Leaves & $\sqrt{ }$ & $\mathrm{X}$ & $\sqrt{ }$ & $\mathrm{X}$ & $\sqrt{ }$ \\
\hline Root & $\sqrt{ }$ & $\mathrm{ND}$ & $\mathrm{ND}$ & $\sqrt{ }$ & $\sqrt{ }$ \\
\hline Key: $(\sqrt{ })=$ Presence, $(\mathrm{X})=$ Absence, $\mathrm{ND}=$ not done \\
\hline
\end{tabular}


Table 2. Evaluations of Ethanolic extracts of Plectanthus barbatus against Late 3rd instars mosquito larvae

\begin{tabular}{|c|c|c|c|c|c|c|c|}
\hline \multirow{2}{*}{ Plants part } & \multirow{2}{*}{ Time interval(hours) } & \multicolumn{3}{|c|}{ Anopheles gambiae } & \multicolumn{3}{|c|}{ Aedes egyptiae } \\
\hline & & $\mathrm{LC}_{50}(\mu \mathrm{g} / \mathrm{ml})$ & $95 \% \mathrm{CI}$ & $100 \% \mathrm{MRC}$ & $\mathrm{LC}_{50}(\mu \mathrm{g} / \mathrm{ml})$ & $95 \% \mathrm{CI}$ & $100 \%$ MRC \\
\hline \multirow{3}{*}{ Leaves } & 24 & $>1000$ & NA & $>1000$ & $\#$ & NA & NA \\
\hline & 48 & 177.69 & $97.42-306.74$ & $>1000$ & $\#$ & NA & NA \\
\hline & 72 & 55.65 & $6.49-477.05$ & 591.23 & $\#$ & NA & NA \\
\hline \multirow{3}{*}{ Roots } & 24 & \# & NA & NA & $\#$ & NA & NA \\
\hline & 48 & $\#$ & NA & NA & $\#$ & NA & NA \\
\hline & 72 & 636.01 & $486.83-986.02$ & $>1000$ & $>1000$ & NA & $>1000$ \\
\hline \multirow{3}{*}{ Twigs } & 24 & $>1000$ & NA & $>1000$ & \# & NA & NA \\
\hline & 48 & 386.66 & $56.07-6028.02$ & $>1000$ & $>1000$ & NA & $>1000$ \\
\hline & 72 & 465.67 & $67.89-869.56$ & $>1000$ & $>1000$ & NA & $>1000$ \\
\hline
\end{tabular}

Key; \# = Not active up to maximum concentration of $80 \mu \mathrm{g} / \mathrm{ml}, \mathrm{NA}=$ not applicable, $\mathrm{MRC}=$ Mortality rate Concentration, $\mathrm{LC}_{50}=\mathrm{Lethal}$ Concentration, $\mathrm{CI}=\mathrm{Confidence}$ interval

Table 3. Cytotoxicity Lethality of Plectanthus barbatus extract against Artemia salina Leach

\begin{tabular}{|c|c|c|c|c|}
\hline $\begin{array}{l}\text { CODE } \\
\text { NAME }\end{array}$ & $\begin{array}{c}\mathbf{L C}_{50} \\
(\mu \mathrm{g} / \mathrm{ml})\end{array}$ & $\begin{array}{l}\text { 95\% Confidence } \\
\text { Interval }(\mu \mathrm{g} / \mathrm{ml})\end{array}$ & $\begin{array}{c}\text { Regression } \\
\text { Equation / } \mathbf{R}^{2}\end{array}$ & $\begin{array}{c}100 \% \mathrm{MRC} \\
(\mu \mathrm{g} / \mathrm{ml})\end{array}$ \\
\hline Leaves & 186.33 & $57.357-605.3116$ & $\begin{array}{c}\mathrm{Y}=62.30 \log \mathrm{x}-91.44 \\
\mathrm{R}^{2}=0.983\end{array}$ & 1182 \\
\hline Twigs & 66.12 & $48.248-90.6108$ & $\begin{array}{c}\mathrm{Y}=82.84 \log \mathrm{x}-100.8 \\
\mathrm{R}^{2}=0.903\end{array}$ & 265 \\
\hline Roots & 40.07 & $22.4295-71.5842$ & $\begin{array}{c}\mathrm{Y}=125.9 \log \mathrm{x}-151.8 \\
\mathrm{R}^{2}=0.898\end{array}$ & 100 \\
\hline
\end{tabular}

Key; $\mathrm{R}^{2}=$ Retention factor, $\mathrm{MRC}=$ Mortality rate concentration, $\mathrm{LC}=$ Lethal concentration

A. gambiae. The findings revealed that, there is no activity towards A.egyptiae up to maximum tested concentration of $80 \mu \mathrm{g} / \mathrm{ml}$, thus the activity trend are in the order of leaves followed by twigs and roots. In the other lethality (Table 3), it revealed that roots are more toxic towards Artemia salina Leach cells with $\mathrm{LC}_{50}$ of $40.07 \mu \mathrm{g} / \mathrm{ml}$ followed by twigs and leaves with $\mathrm{LC}_{50}$ of $66.12 \mu \mathrm{g} / \mathrm{ml}$ and $186.33 \mu \mathrm{g} / \mathrm{ml}$ respectively. The activity trend of $\mathrm{P}$. barbatus towards brine cells are in order of roots followed by twigs and leaves. These trend comply with the traditional uses of these parts of plant as indicated in the literature [16-20] .Generally, these findings reflect the recently research done in Tanzania in which the plant species showed the potency of mosquito larvicidal in the laboratory trials $[31,32]$.

Thus, the correlation of both mosquito larvicidal and Brine shrimp lethality showed that twigs have mildly activity in both bio-assays while leaves showed more activity on mosquito larvae specifically A. gambiae. These findings are more interesting since leaves do not affect the diversity of plants species and consequently is in line with biodiversity conservation. In Brine shrimp test, roots showed remarkable activity correlated to the traditional used.

\section{Conclusion}

These findings revealed that there is no direct connection between cytotoxicity and mosquito larvicidal activity towards the plant parts of $P$. barbatus. Since, leaves showed remarkable mosquito larvicidal activity towards A. gambiae and roots possessed strong activity towards Artemia salina cells. Thus the plant demonstrate their pharmacological potentials as it has been used for treatments of various diseases since time memorial.

\section{Acknowledgement}

The authors are grateful to Dr. H.M. Malebo, Head of Department of Traditional Medicine, National Institute for Medical Rresearch (NIMR-MABIBO) for allowing the team to conduct research in the laboratory. Also to $\mathrm{Mr} \mathrm{H}$. Seleman, the senior Botanist of the University of Dar es Salaam for the identification of the plant materials.

\section{Competing interests}

The authors declare that they have no competing interests.

\section{References}

1. Das MK, Ansari MK (2003) Evaluation of repellent action of Cymbopogan martin martini Stapf var Sofia oil against Anopheles sundiacus in tribal villages of Car Nicobar Island, Andaman \& Nicobar Islands, India. J Vect Borne Dis 40: 101-114. [Crossref]

2. White GB (1974) Anopheles gambiae complex and disease trans-mission in Africa. Trans R Soc Trop Med Hyg 68: 278-301. [Crossref]

3. Ringu-Perez JG, Clark GG, Gubler DJ (1997) Dengue and Dengue hemorrhagic fever Lancet 7: 352-971. [Crossref]

4. Malavige GN, Fernando S, Fernando DJ, Seneviratne SL (2004) Dengue vira infections. Postgrad Med J 80: 588-601. [Crossref]

5. Pavel R (2007) Possibilities of botanical insecticide exploitation in plant protection Pest Tech 1: 47-52.

6. Hag EL, Nadi EA, EI AH, Zaitoon AA (1999) Toxic and growth retarding effects of 3 plant extracts on Culex pipiens (Diptera;Culicidae). Phytother Res 13: 388-392. [Crossref]

7. Palsson K, Jaenson TG (1999) Plant products used as mosquito repellents in Guinea Bissau, West Africa. Acta Trop 72: 39-52. [Crossref]

8. Bloom DE, Canning D, Sevilla J (2004) The Effect of Health on Economic Growth: A Production Function Approach. World Development 32: 1-13.

9. WHO \& UNICEF (2012) World Malaria Report. Geneva: World Health Organization.

10. National Malaria Control Programme (NMCP), (2010). National Malaria Control Programme Monitoring and Evaluation Plan, 2008-2013, Dar es Salaam; Tanzania: MOHSW, United Republic of Tanzania.

11. WHO (2008). Dengue and dengue haemorrhagic fever. Geneva, World Health Organization.

12. Halstead SB, Suaya JA, Shepard DS (2007) The burden of dengue infection. Lancet 369: 1410-1411. [Crossref]

13. Moi ML, Takasaki T, Kotaki A, Tajima S, Lim CK, Sakamoto I, et al. (2010) Importation of dengue virus type 3 to Japan from Tanzania and Co ${ }^{\wedge}$ te d' Ivore. Emerg Infect Dis 16: 1770-1772. [Crossref]

14. Hertz JT, Munishi OM, Ooi EE, Howe S, Lim WY, et al. (2012) Chikungunya and dengue fever among hospitalized febrile patients in northern Tanzania. Am J Trop Med Hyg 86: 171-177. [Crossref] 
15. Lukhoba CW, Simmonds MSJ, Paton AJ (2006) Plectranthus: A review of ethnobotanical uses. J Ethnopharmacol 103: 1-24. [Crossref]

16. Alasbahi RH, Melzig MF (2010) Plectranthus barbatus: a review of phytochemistry, ethnobotanical uses and pharmacology - Part 1. Planta Med 76: 653-661. [Crossref]

17. Dubey MP, Srimal RC, Nityanand S, Dhawan BN (1981) Pharmacological studies on coleonol,a hypotensive diterpene from Coleus forskohlii. J Ethnopharmacol 3: 1-13. [Crossref]

18. Zelnik R, Levy EC, Wang AHJ, Paul IC (1977) Barbatusin and cyclobutatusin,two noval diterpenoids from Coleus barbatus Bentham. Tetrahedron 33:1 457-1467.

19. Dubey MP, Srimal RC, Patnaik GK, Dwawan BN (1974) Hypotensive and spasmolytic activities of coleonol,active principle of Coleus forskohlii Briq. Indian J Pharmacol 6: 15.

20. Ammon HP, Kemper FH (1982) Ayurveda: 3000 years of Indian traditional medicine. Med Welt 33: 148-153. [Crossref]

21. Ammon HP, Miller AB (1985) Forskolin; from an Ayurvedic remedy to a modern agent. Planta Med 6: 473-477. [Crossref]

22. De Souza NJ, Shah V (1988) Forskolin-an adenylate cyclase activating drug from an Indian herb. Econ Med Plant Res 2: 1-16.

23. Misra LN, Tyagi BR, Ahmed A, Bahl JR (1994) Variability in the chemical composition of the essential oil of Coleus forskohlii genotypes. J Essent Oil Res 6: 243-247.

24. Chowdhary AR, Sharma ML (1998) GC-MS investigations on the essential oil from Coleus forskohlii Briq. Indian Perfumer 42: 15-16.
25. Meyer BN, Ferrign NR, Putnam JE, Jacobson IB, Nicholas DE, et al. (1982) Brine Shrimp: A Convenient General Bioassay for Active Plant Constituents. Planta Medica 45: 31-34. [Crossref]

26. Funney DJ (1971) Probit Analysis, 3rd ed.Cambridge University Press. Cambridge, England 25-325.

27. WHO, World Health Organization (1996) Protocols for Laboratory and Field Evaluation of Insecticides and Repellents: Report of the WHO Informal Consultation on the Evaluation and testing of Insecticides. Ref: CTD/WHOPES/IC/96.1.Geneva.

28. Odebiyi A, Sofowora EA (1978) Phytochemical screening of Nigeria medicinal plants II. Lioydia 403: 234-246. [Crossref]

29. Williamson EM, Okpako DG Evan FJ (1996). Pharmacological methods in phytotherapy research. Selection. Preparation and Pharmacological evaluation of plant materials. John Wiley and Sons Ltd. Chichester. England 1: 9-13.

30. Banso A, Ngbede JE (2006) Phytochemical screening and in vitro antifungal properties of Fagara zanthoxyloides. JFA and E (3 and 4): 8-9.

31. Nondo RSO, Mbwambo ZH, Kidukuli AW, Innocent EM, Mihale MJ, et al. (2011) Larvicidal, antimicrobial and brine shrimp activities of extracts from Cissampelos mucronata and Tephrosia villosa from coast region, Tanzania. BMC Complement Altern Med 11: 33. [Crossref]

32. Wilson E, Chacha M, Omolo JJ, Kidukuli A (2014) Larvicidal activity of leaf and stem extracts of Sterculia quinqueloba (Garcke) K. Schum Against the Anopheles gambiae Giles S.S, Culex quinquefasciatus Say and Aedes egyptiae Mosquito. AJRC 2: 61-71.

Copyright: $\odot 2018$ Lawi Y. This is an open-access article distributed under the terms of the Creative Commons Attribution License, which permits unrestricted use, distribution, and reproduction in any medium, provided the original author and source are credited. 